\title{
Reaction Mechanism of the Metal Precursor Pulse in Plasma- \\ Enhanced Atomic Layer Deposition of Cobalt and the Role of Surface Facet
}

\author{
Ji Liu ${ }^{\mathrm{a}}$, Hongliang Lư ${ }^{\mathrm{b}}$, David Wei Zhang, and Michael Nolan, ${ }^{\mathrm{a}, *}$ \\ ${ }^{a}$ Tyndall National Institute, University College Cork, Lee Maltings, Dyke Parade, Cork, T12 \\ R5CP, Ireland \\ b State Key Laboratory of ASIC and System, Shanghai Institute of Intelligent Electronics \& \\ Systems, School of Microelectronics, Fudan University, Shanghai 200433, China
}

Corresponding author:

*E-mail: Michael.nolan@tyndall.ie. Tel: +353 0212346983 
Table S1. The calculated reaction energy for hydrogen transfer step and reaction barriers on $\mathrm{Co}(001)$ and (100) surfaces with $\mathrm{NH}_{\mathrm{x}}$ terminations corresponding to zero $\mathrm{K}$ condition. $\mathrm{E}_{\text {adsorption }}$ is the energy change upon precursor adsorption, $\mathrm{E}_{\text {hydrogen }}{ }^{\mathrm{I}}$ and $E_{\text {hydrogen }}{ }^{I I}$ are the energy change for the first and second hydrogen transfer, and $\mathrm{E}^{\mathrm{Des}} \mathrm{CpH}^{\mathrm{I}}$ is the desorption energy of $\mathrm{CpH}$.

\begin{tabular}{|c|c|c|c|c|c|c|}
\hline & \multicolumn{3}{|c|}{$H^{*}+\operatorname{CoCp}_{2} \rightarrow \operatorname{CoC} p^{*}+H C p$} & \multicolumn{3}{|c|}{$H^{*}+C o C p \rightarrow C o^{*}+H C p$} \\
\hline & $\mathrm{E}_{\text {adsorption }}$ & $\mathrm{E}_{\text {hydrogen }}{ }^{\mathrm{I}}$ & $\mathrm{E}_{\text {barrier }}$ & $\mathrm{E}^{\mathrm{Des}}{ }_{\mathrm{CpH}}^{\mathrm{I}}$ & $\mathrm{E}_{\text {hydrogen }}{ }^{\mathrm{II}}$ & $\mathrm{E}_{\text {barrier }}$ \\
\hline $\mathrm{Co}(001)$ & -0.10 & -0.76 & 1.00 & -2.34 & -2.46 & 1.24 \\
\hline $\operatorname{Co}(100)$ & -1.73 & -3.12 & 1.56 & -1.17 & -1.72 & 0.84 \\
\hline
\end{tabular}




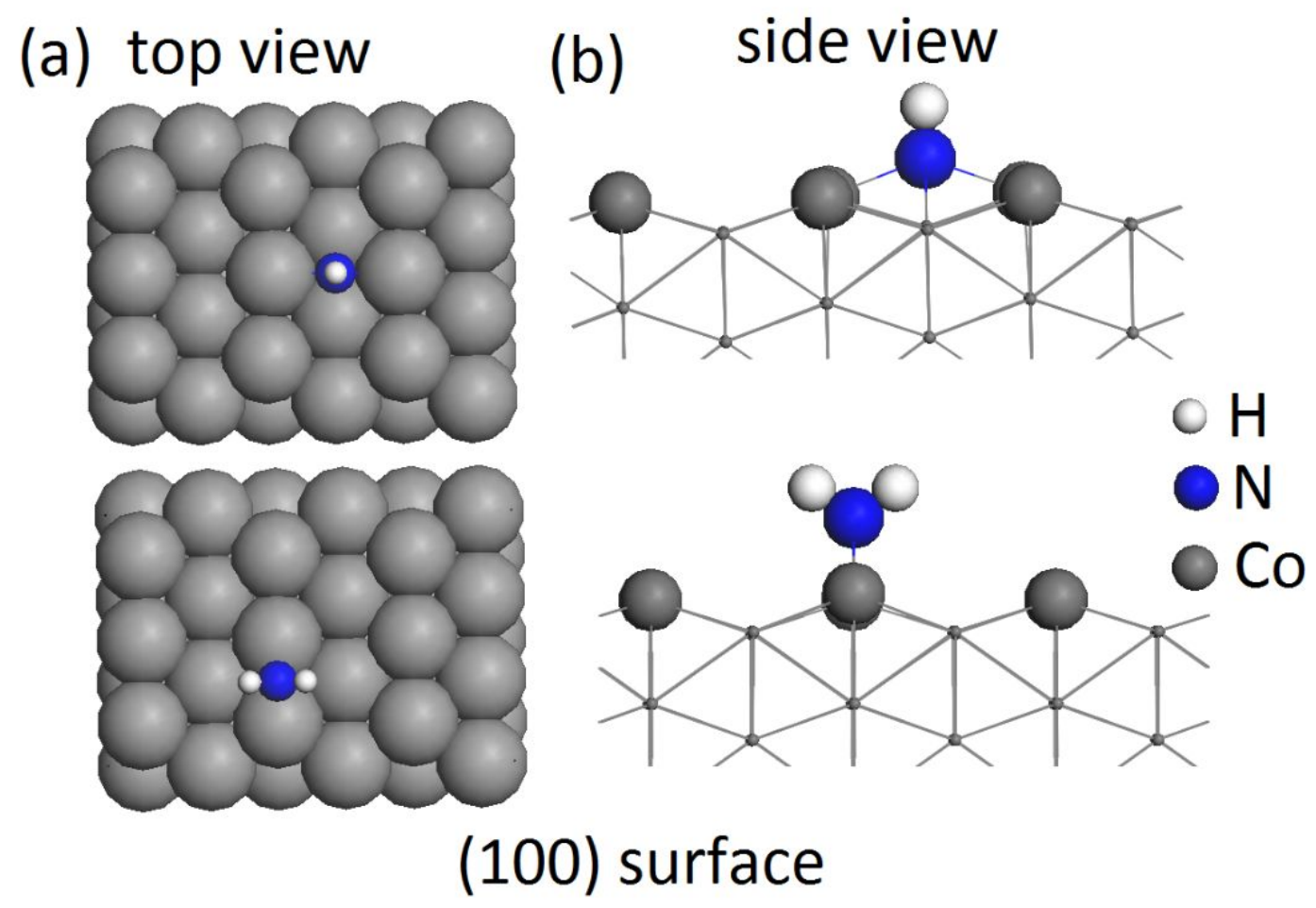

Figure S1. The configurations of the (a) top view and (b) side view of single $\mathrm{NH}$ and $\mathrm{NH}_{2}$ adsorbed on $\mathrm{Co}(100)$ surface. $\mathrm{NH}$ prefers channel bridge and $\mathrm{NH}_{2}$ prefers surface bridge site. 

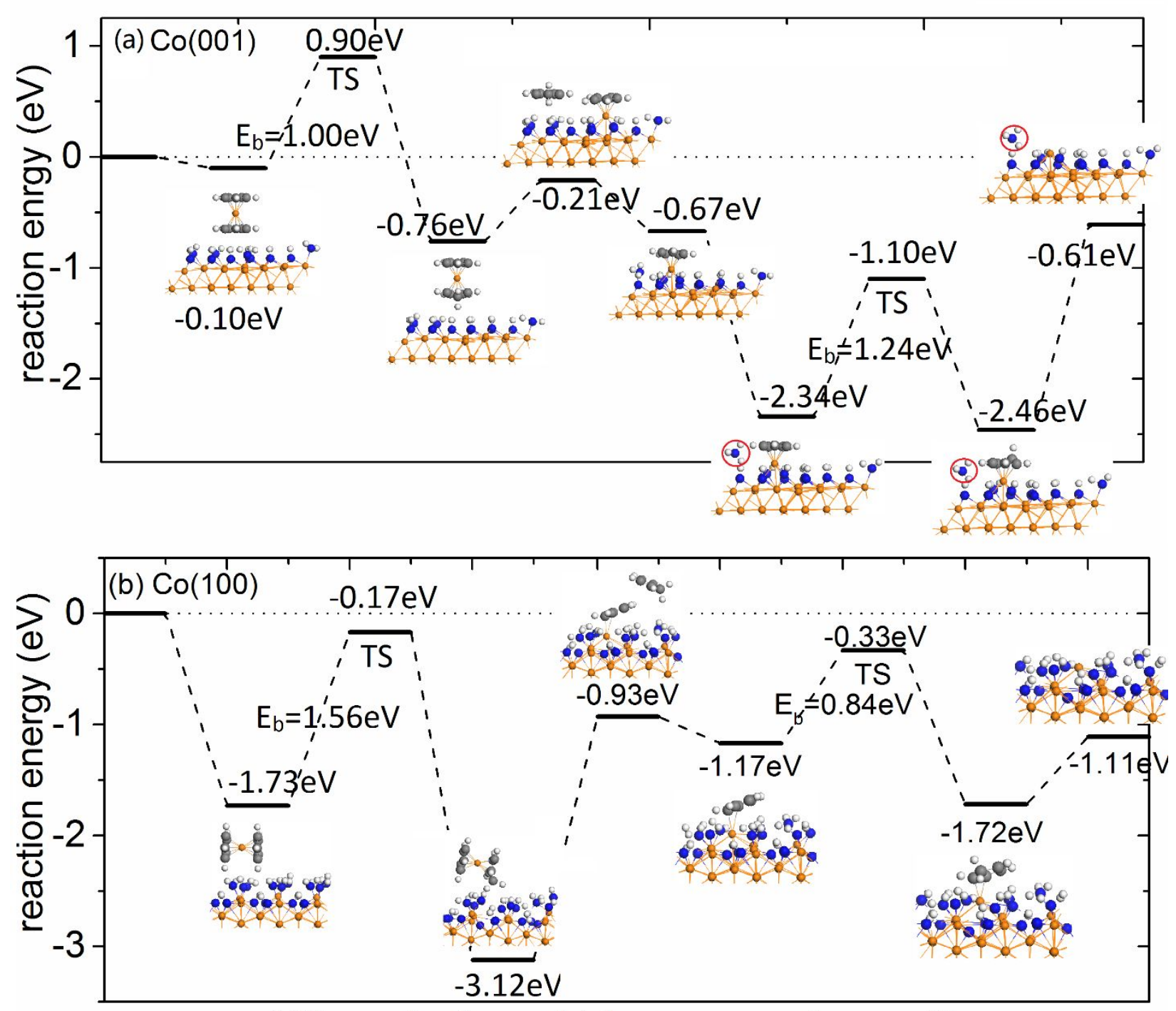

$\mathrm{NH}_{\mathrm{x}}$ terminations at highest coverage, i.e. zero $\mathrm{K}$

Figure S2. The plotted metal precursor reaction pathway on (a) $\operatorname{Co}(001)$ surface and (b) $\operatorname{Co}(100)$ surface with $\mathrm{NH}_{\mathrm{x}}$ terminations at zero $\mathrm{K}$ condition. The $\mathrm{Cp}$ ligand is eliminated via hydrogen transfer. The Co atom is represented by orange color and carbon, nitrogen and hydrogen atoms are represented by grey, blue and white color, respectively. On $\mathrm{Co}(001)$ surface, there is $\mathrm{NH}_{3}$ formation during the $\mathrm{Cp}$ ligand elimination process. 